\title{
An in vitro bacterial adhesion assessment of surface-modified medical-grade PVC
}

\author{
Ahmad Asadinezhad ${ }^{3}$, Igor Novák ${ }^{b}$, Marián Lehockýc’*, Vladimir Sedlařik ${ }^{3}$, Alenka Veseld, \\ ItaJunkard, Petr Sáhaa, Ivan Chodák ${ }^{0}$
}

A B S T R A C T

Medical-grade polyvinyl chloride was surface modified by a multistep physicochemical approach to improve bacterial adhesion prevention properties. This was fulfilled via surface activation by diffuse coplanar surface barrier discharge plasma followed by radical graft copolymerization of acrylic acid through surfaceinitiated pathway to render a structured high density brush. Three known antibacterial agents, bronopol, benzalkonium chloride, and chlorhexidine, were then individually coated onto functionalized surface to induce biological properties. Various modern surface probe techniques were employed to explore the effects of the modification steps. In vitro bacterial adhesion and biofilm formation assay was performed. Escherichia coli strain was found to be more susceptible to modifications rather than Staphylococcus aureus as up to $85 \%$ reduction in adherence degree of the former was observed upon treating with above antibacterial agents, while only chlorhexidine could retard the adhesion of the latter by $50 \%$. Also, plasma treated and graft copolymerized samples were remarkably effective to diminish the adherence of E. coli.

\section{Introduction}

Various strains of bacteria are capable of adherence and proliferation on biomedical polymers leading to serious nosocomial contaminations $[1,2]$. In this situation, the implant has to be taken away because of the poor success of the treatment; hence, much emphasis has been laid on practical ways to thwart device-related infections via delivering anti-infective polymeric implants [3]. However, this can be accomplished through compounding with antibacterial agents, but such a conventional technology demands large quantities of antibacterial agents and since they are not immobilized on the surface, subsequent to implantation, a gradual release of the biocides occurs inside the human body posing health concerns [4].

Surface modification is a straightforward strategy to render antiadherence quality which deters the susceptibility to bacterial adhesion [5]. This can be achieved by deposition of thin antibacterial layers tethered to the surface of polymeric support already chemically grafted with a spacer of a brush-like pattern. This multistep approach has aroused great interest thanks to several advantages such as convenient and controllable introduction of biocidal species with a high surface density together with precise localization and long stability of the grafted layers [6,7]. In the first phase, a preliminary functionalization has to be achieved regarding an inherent lack of active entities on the pristine substrate, where low temperature-atmospheric pressure plasma treatment has been proved to be effective therein [8,9]. However, the necessity to shorten the treatment duration to a few seconds calling for rather high plasma power density remains a critical impediment to largescale applications of this type of plasma [10]. To resolve the shortcomings, an innovative discharge technology has been developed [11], capable of generating a homogeneous plasma layer under ambient pressure with a high power density in the immediate vicinity of the treated surface, namely, diffuse coplanar surface barrier discharge (DCSBD). It is based on surface dielectric barrier discharge with a high density of fine discharge streamers generated on a dielectric surface in parallel with the sample surface $[12,13]$. In the second step of the procedure, an end-functionalized polymer brush monolayer is formed onto the surface preferably via graftingfrom pathway assisting the formation of a thick layer of high grafting density on the surface using generation of appropriate initiators attached to the substrate in which monomers are able to easily penetrate through the already-grafted layer and contribute to the chain growth [14-16]. As the final step, antibacterial 


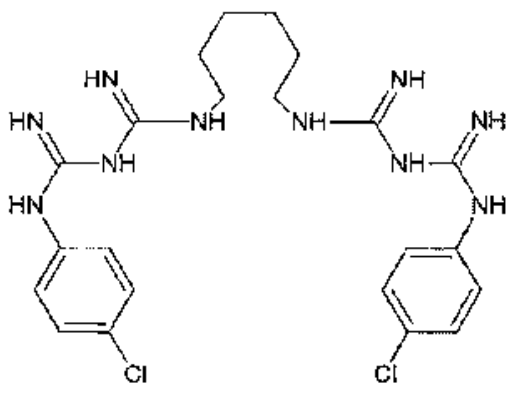

Chorhexidine

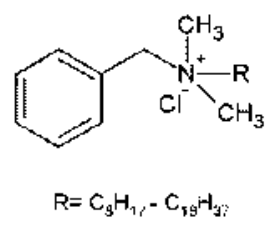

Eerzalkonium chloride

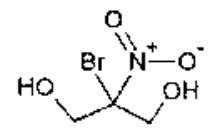

Bronopol

Fig. 1. Structural formulas of three employed antibacterial agents.

species are immobilized onto this platform to convey the desired biological activities. To ensure immobilization, a fixative may be added, depending on the existing chemical functionalities of the antibacterial molecules to induce crosslinking [17].

Benzalkonium chloride is one of the safest synthetic biocides known as yet which is classified as a quaternary ammonium compound (Fig. 1) currently used in human pharmaceuticals [18,19]. Another efficient biocide, that exhibits immediate, long term antibacterial effectiveness as well as marginal toxicity in clinical use, is bronopol (2-bromo-2-nitropropane-1,3-diol) (Fig. 1) used in consumer products as an effective preservative agent, as well as in a wide variety of industrial applications [20,21]. Chlorhexidine, (1,1'-hexamethylene bis[5-(4-chlorophenyl)biguanide]) (Fig. 1), is a clinically important biocide, disinfectant, and preservative which exists in oral rinses and skin cleansers, and, in small quantities, it is used as a preservative [22,23]. A limited number of published papers have been devoted hitherto to study the above antibacterial agents as biological coatings on polymeric supports [21,24-29]. Zhang et al. [21,24] immobilized bronopol entities on medicalgrade polyethylene (PE) [21] and PVC [24] by means of plasma treatment and reported excellent antibacterial properties against Staphylococcus aureus (S. aureus) and Escherichia coli (E. coli) strains. They also investigated bacterial adhesion on the modified samples and observed a low number of active adhered bacteria. The same authors [25] reported that the modified PE samples coated with bronopol exhibited excellent bactericidal effects against $E$. coli and $S$. aureus when the bacteria concentration in the suspension was $10^{6} \mathrm{CFUmL}^{-1}$. However, when the concentration exceeded $10^{8}$ $\mathrm{CFUmL}^{-1}$, the samples failed to develop noticeable resistance towards a large number of bacteria on account of the bacterial biofilm formation on the surfaces. Harnet et al. [26] investigated the antibacterial effects obtained with chlorhexidine-functionalized polyelectrolyte films built on different types of suture materials and reported an inhibition of E. coli proliferation by $40 \%$ and $99 \%$ after 24 and $48 \mathrm{~h}$ incubation periods, respectively. Adams et al. [27] gave an account of the enhanced antisepsis efficacy of $2 \%$ $(\mathrm{w} / \mathrm{v})$ chlorhexidine in $70 \%(\mathrm{v} / \mathrm{v})$ isopropyl alcohol compared to the equal concentration of the same material in pure water used as a common skin disinfectant solution. Yao et al. [28] reported a highly efficient antibacterial layer on PU fibrous membranes obtained from quaternary ammonium entities. In another study, Thome et al. [29] developed novel antibacterial coatings on PE films from various innocuous polyammonium compounds and reported a reduced settlement of bacteria such as Micrococcus luteus and $E$. coli by a factor of $10^{5}-10^{6}$ after treatment. More attempts have yet to be made to further spotlight the issues surrounding the interactions of above antibacterial agents and pathogenic bacteria.

The main focus of this unprecedented work is directed at deposition of the above described antibacterial agents onto medical-orade
PVC using the multistep physicochemical approach and to assess and compare the subsequent anti-adherence properties against both gram-positive and gram-negative bacteria. Surface characterizations are also implemented by means of various probe techniques to examine surface characteristics and the acquired data are discussed. The broad application window of medical-grade PVC as a leading biomedical polymer underlies the motivation of choosing this material as a target for the current work.

\section{Materials and methods}

\subsection{Materials}

PVC pellets, extrusion medical-grade RB1/T3M of 1.25 gem $^{-3}$ density, were obtained from ModenPlast (Italy) and used as received. Bronopol (2-bromo-2-nitro-1,3-propanediol) $\quad(98.0 \%$, purum), acrylic acid (99.0\%, anhydrous), and $\mathrm{N}$-(3-dimethyl aminopropyl)-N'-ethyl carbodiimide hydrochloride (EDAC, 98.0\%) were supplied by Fluka (USA). Absolute ethanol (99.8\%, spectranal) was obtained from Riedel-de Haen (Germany). Benzalkonium chloride with the predominant chemical formula of CizHzsNfCHahCyHyCl, chlorhexidine (1.V-hexamethylene bis[5- (4chlorophenyl)biguanide], 98\%), sodium metabisulfite $(99.0 \%$, reagentplus), glutaraldehyde (as $25.0 \mathrm{wt} \%$ aq. solution), ethylene glycol, (99.8\%, anhydrous), diiodomethane (99.0\%, reagentplus), formamide $(99.5 \%$, molecular biology grade), and Triton X-1 00 (laboratory grade) were all supplied by Sigma-Aldrich (USA).

\subsection{Substrates preparation}

PVC granules were moulded by hot pressing at $165{ }^{\circ} \mathrm{C}$ for 10 min, formed into flat sheets of $1 \mathrm{~mm}$ thickness, and subsequently cut into $4 \mathrm{~cm} \times 5 \mathrm{~cm}$ pieces after cooling. The substrates were then washed thoroughly by rinsing with dilute ethanol, sonicating first with $0.1 \%(\mathrm{v} / \mathrm{v})$ aq. solution of non-ionic surfactant (Triton X-1 00), and then with deionized water at $30^{\circ} \mathrm{C}$ for $10 \mathrm{~min}$. Finally, they were dried in an air-circulating oven at $30{ }^{\circ} \mathrm{C}$ for $24 \mathrm{~h}$.

\subsection{Plasma treatment}

Plasma treatment was implemented in static conditions using the DCSBD technology of laboratory scale with air as the gaseous medium at atmospheric pressure and ambient temperature. A schematic representation of the plasma system is given in Fig. 2. It basically consists of a series of parallel metallic electrodes inlaid in a ceramic dielectric which are located inside a glass chamber which allows the carrier gases to flow. All samples were treated on both sides with plasma power of $200 \mathrm{~W}(1.1 \mathrm{~A})$ for $15 \mathrm{~s}$. 


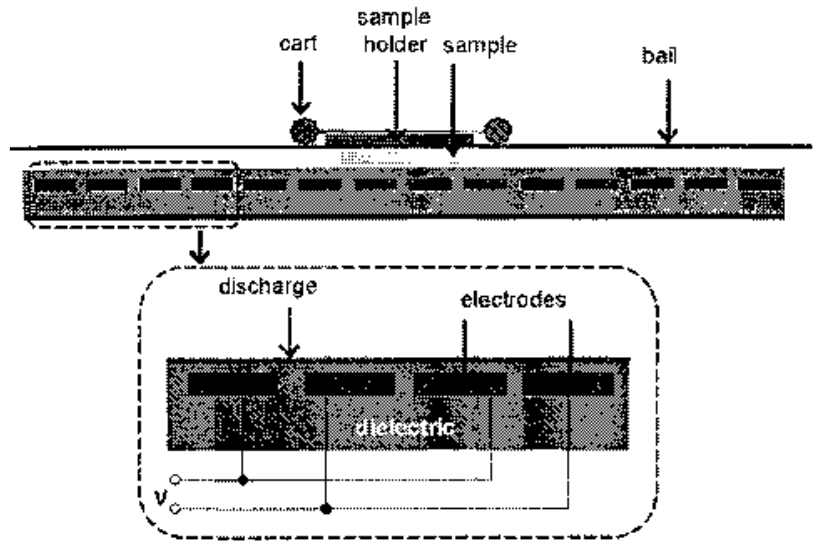

Fig. 2. Schematic representation of DCSBD plasma system.

\subsection{Graft copolymerization}

PVC substrates, upon treatment with plasma, were immersed into spacer solutions containing $10 \%(\mathrm{v} / \mathrm{v})$ acrylic acid (AA) aq. solution. To ensure a radical graft copolymerization of AA onto PVC following the surface-initiated pathway (Fig. 3a), 0.1 wt.\% sodium metabisulfite was added an efficient reductant to inhibit AA homopolymerization [30]. The reaction was permitted to proceed at $30{ }^{\circ} \mathrm{C}$ for $24 \mathrm{~h}$. The samples were taken out of the solutions, washed with $0.05 \%(\mathrm{v} / \mathrm{v})$ Triton X-100 aq. solution and also deionized water in an ultrasonic bath for $5 \mathrm{~min}$ at $30{ }^{\circ} \mathrm{C}$ to remove any unbound polyacrylic acid (PAA) species on the surface. Drying was carried out in an air-circulating oven under $30{ }^{\circ} \mathrm{C}$ for $24 \mathrm{~h}$.

2.5. Antibacterial agents deposition

PVC-grafted-polyacrylic acid samples were immersed into $0.1 \%$ $(\mathrm{w} / \mathrm{v})$ EDAC aq. solution at $4^{\circ} \mathrm{C}$ for $6 \mathrm{~h}$ in order to activate the carboxyl groups on the surface. The activation mechanism is outlined in Fig. 3b, where a highly active key intermediate, O-acylisourea, is produced having potential to react with reducing agents [31 ]. Subsequent to carboxyl activation, the substrates were transferred to solutions containing antibacterial agents, that is, $2 \%(\mathrm{w} / \mathrm{v})$ bronopol in absolute ethanol, $2 \%(\mathrm{w} / \mathrm{v})$ benzalkonium chloride aq. solution, and $2 \%(\mathrm{w} / \mathrm{v})$ chlorhexidine in isopropanol $70 \%(\mathrm{v} / \mathrm{v})$ aq. solution, and kept there at $30{ }^{\circ} \mathrm{C}$ for $24 \mathrm{~h}$ in order to coat the surface with antibacterial molecules (Fig. 3a). To ensure immobilization of chlorhexidine, due to the presence of amine groups, the samples, after having been rinsed several times with deionized water, were dipped into $1 \%(\mathrm{w} / \mathrm{v})$ glutaraldehyde aq. solution at $4^{\circ} \mathrm{C}$ overnight acting as an amine-reactive homobifunctional fixative

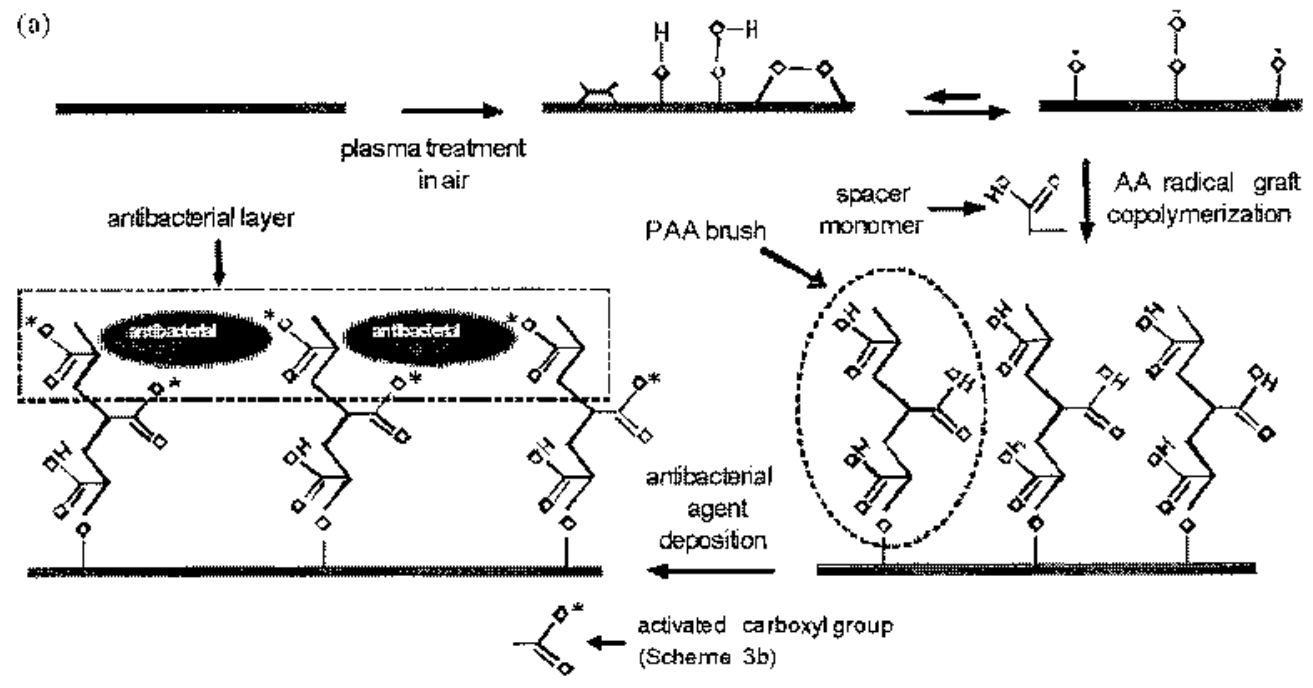

(b)<smiles>CCN=C=NCCCN(C)CC(=O)OC(=NCCCN(C)C)OC(=O)C(C)(C)C</smiles>

(c)

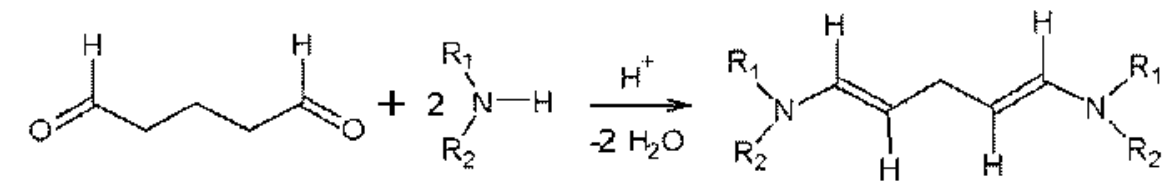

Fig. 3. Multistep strategy for antibacterial agents deposition onto PVC substrate (a), carboxyl group activation mechanism by EDAC (b), and enamine formation following secondary amine and glutaraldehyde reaction (c). 
to immobilize chlorhexidine species onto the surface via crosslinking. Crosslinking takes place by enamine formation as a result of a reaction between secondary amine and glutaraldehyde [32], as depicted in Fig. 3c. All of samples were finally washed and dried following the procedure described above.

\subsection{Surface wettability assessment}

The wettability of the samples was evaluated using contact angle analysis and water absorption test. Static contact angle measurements by the sessile drop method were carried out via Surface Energy Evaluation (See) System (Advex Instruments) equipped with a CCD camera using a set of standard testing liquids at $22{ }^{\circ} \mathrm{C}$ and $60 \%$ relative humidity. The data analysis was performed via the See System software. Each resulting contact angle was an average of 10 measured values recorded $30 \mathrm{~s}$ after reposing each drop of 5 JuLL volume on the sample surface. Water absorption test was implemented by exposing each specimen to water at $22{ }^{\circ} \mathrm{C}$ for $24 \mathrm{~h}$ and gently padding with a filter paper to eliminate the unabsorbed water. The results were reported as a percentage of water absorption ([(wet weight-dry weight)/dry weight] $\mathrm{x}$ 100) after taking means of three replicates.

\subsection{Surface morphology examination}

Scanning electron microscopy (SEM) was carried out on VEGA IILMU (TESCAN) operating in the high vacuum/secondary electron imaging mode at an accelerating voltage of $5-20 \mathrm{kV}$. The samples were sputter coated with a thin layer of palladium/gold alloy and tilted $30^{\circ}$ to reach enhanced resolution and observation of the surface topography. The images were taken at $30000 \mathrm{x}$ magnification.

\subsection{Surface chemistry examination}

ATR-FTIR spectra were collected at a spectral resolution of $2 \mathrm{~cm}^{-1}$ via Avatar 320 FT-IR spectrometer (Nicolet) equipped with $\mathrm{ZnSe}$ crystal at an incident angle of $45^{\circ}$. Each spectrum represents 64 co-added scans rationed against a reference spectrum obtained by recording 64 co-added scans of an empty ATR cell. The acquired spectra were analyzed using OMNIC Software Suite. X-ray Photoelectron Spectroscopy (XPS) was conducted using TFA XPS Physical Electronics. The base pressure in the XPS analysis chamber was «6 $610 \sim^{8} \mathrm{~Pa}$. The samples were excited by X-rays over a 400-(xm diameter spot area with a monochromatic Al Kai, 2 radiation at $1486.6 \mathrm{eV}$. The emitted photoelectrons were detected by a hemispherical analyzer positioned at a take-off angle of $45^{\circ}$. Survey-scan spectra were obtained at a pass energy of 187.85 and $0.4 \mathrm{eV}$ step resolution. An electron gun was employed for surface neutralization. The elemental concentration analysis was performed over three different positions by MultiPak v7.3.1 software.

\subsection{In vitro bacterial adhesion test}

Bacterial adhesion and biofilm experiments were performed using gram-positive (S. aureus 3953) and gram-negative (£. coli 3954) bacteria. The circular shape specimens (d " $8 \mathrm{~mm}$ ) were cut from the pristine and modified PVC samples before further investigation. The bacterial adhesion was performed as follows, the test tubes with $10 \mathrm{~mL}$ of sterile water solution of nutrient broth (Envitech, Czech Republic) were inoculated with given bacterial strain to reach $\wedge 10^{8} \mathrm{CFUmL}^{-1}$ and left at room temperature for 30 min. Then, the specimens were inserted into the test tubes. After $24 \mathrm{~h}$ incubation at $37{ }^{\circ} \mathrm{C}$ under continuous shaking at $100 \mathrm{rpm}$, the test tubes were opened and the specimens were carefully removed from the medium, rinsed with sterile distilled water to loosely adhered bacteria and placed into other test tubes containing $2 \mathrm{~mL}$ of sterile deionized water. The bacteria adhered on the surface of the specimens were removed by vigorous shaking of the test tube at $2000 \mathrm{rpm}$ for $30 \mathrm{~s}$ and quantified by serial dilutions and spread plate technique. A $1 \mathrm{~mL}$ aliquot of the suspension was diluted decimally and from each dilution, $0.1 \mathrm{~mL}$ was transferred to a nutrient agar plate and the surviving bacteria were counted after $24 \mathrm{~h}$ of cultivation at $37{ }^{\circ} \mathrm{C}$ reported as CFU $\mathrm{cm}^{-2}$. Each experiment was repeated in triplicate.

\section{Results and discussion}

\subsection{Surface wettability analysis}

The contact angle values of deionized water $\left(\mathrm{O}_{\mathrm{w}}\right)$ on different specimens are provided in Table 1 . For convenience, each sample has been assigned a number from 1 to 6 whose notation is given in the table title. Based on the acquired data, sample 1 shows a hydrophobic surface where upon treating with DCSBD plasma (sample 2), an obvious change in $O_{W}$ occurs and the hydrophilicity increases expectedly. This trend sustains concerning sample 3 on which PAA chains are grafted as a stronger hydrophilic tendency is exhibited regarding $O_{W}$. The hydrophilicity decreases as antibacterial agents are coated onto the surface (samples 4-6), yet, it is well above than that of sample 1 . The induced hydrophilicity upon multistep modifications is surmised to stem from the formation of hydrophilic groups on the surface in particular in the case of sample 3 [33-35]. To delve further into the surface physicochemical variations of the samples, a widely used theory, Lifshitz-van der Waals/acid-base (LW/AB) [36], has been employed to estimate free surface energy values whose outputs based on diiodomethane, ethylene glycol, and deionized water as wetting agents are given in Table 1. As suggested by the data, sample 1 shows a basic nature $\left(Y^{\sim}>\mathrm{X}^{+}\right)$. however acidity or basicity of neat PVC has been a matter of dispute [ $1,36,37]$. Upon treating with plasma (sample 2), the total surface free energy $\left(y^{\text {tot }}\right)$ increases concerning an evident change in contact angle values. This increase is mainly contributed by the polar (acid-base) component $\left(y^{\mathrm{AB}}\right)$, rather than by the dispersion one $\left(\mathrm{y}^{\mathrm{LW}}\right)$, implying an introduction of polar oxygencontaining entities to the surface owing to the plasma treatment. A drastic rise in $y^{\text {tot }}$ and $y^{A B}$ values is evident for sample 3, compared to the samples 1 and 2 , signifying the presence of polar carboxylcontaining units on the surface. A sharp decrease is observed in $y^{A B}$ and $y^{\wedge t}$ values of samples 4-6 compared to the sample 3, however, $y^{\text {tot }}$ of the former goes beyond that of sample 1. It is worth noting that the lowest $O E$ is observed for sample 5 giving the impression that the surface is most likely covered with species containing alcoholic functionality which in fact points to bronopol. Also, sample 4 shows the maximum $y^{A B}$ compared to the samples 5 and 6 as it is deduced from ionic structure of benzalkonium chloride. Sample 6 exhibits the minimum hydrophilicity and $y^{\text {tot }}$ compared to samples 4 and 5. To draw a parallel between LW/AB theory and equation of state models, the predictions for surface free energy values of samples 1-6 based on three equation of state models [36] (Kwok-Neumann, Li-Neumann, and Wu) using four wetting agents are reported in Table 1. Although they yield lower outputs compared to $\mathrm{LW} / \mathrm{AB}$ approach, the variation trend indicated from samples 1 to 6 is maintained. The $\mathrm{Wu}$ equation of state, on account of its fundamental assumptions, gives closer values to those from $\mathrm{LW} / \mathrm{AB}$ approach.

The results obtained from contact angle measurements are substantiated by the information obtained from water absorption test given as histograms in Fig. 4. It is perceived from the data that the capacity for water absorption may be aided by an improvement in the surface tension as confirmed by several researchers $[3,38-40]$. Indeed, the hydrophilic modification is verified by the capacity for water absorption. The modified samples (samples 26) 
Table 1

Contact angle analysis results of samples 1-6 using deionized water (w), ethylene glycol (E), diiodomethane (D), and formamide (F) as wetting agents. Sample 1: control/pristine; sample 2: plasma treated; sample 3: PAA grafted; sample 4: benzalkonium chloride coated; sample 5: bronopol coated; sample 6: Chlorhexidine coated (mean ${ }_{\mathcal{L}} \operatorname{standard~} \mathrm{deviation}$ ).

\begin{tabular}{|c|c|c|c|c|c|c|c|c|c|c|c|c|}
\hline Spccimen: & $\theta_{w}(5)$ & $\theta_{e}(")$ & $N_{0}(4)$ & $d_{F}(j)$ & $\begin{array}{l}y_{\text {LW;iH }}^{-} \\
\left(\mathrm{m}_{\mathrm{j}} / \mathrm{m}^{2}\right)\end{array}$ & 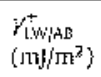 & 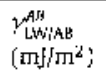 & 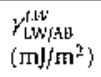 & 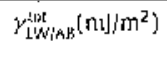 & $\begin{array}{l}\gamma w t^{a} \\
{\left[: T h \int^{\prime} m^{2}\right)}\end{array}$ & $\begin{array}{l}\left.\gamma \mathrm{kN}\right|^{b} \\
\left.(\mathrm{~m}] / \mathrm{m}^{2}\right)\end{array}$ & $\begin{array}{l}Y \mathrm{~N} \\
\left.(\mathrm{~m}) \mathrm{j}^{2}\right)\end{array}$ \\
\hline Sample 1 & $85.9( \pm 2.5)$ & $60.5(1.30)$ & $43.5[ \pm 3.5\}$ & $64.2(-1, \sqrt{6}, 0)$ & 5.1 & 0,0 & 1.0 & 37,8 & 38.8 & 37.8 & 33,3 & 33.6 \\
\hline Sanple 2 & $64,9(+, 3,0)$ & $49,4( \pm 4,0)$ & $36.2( \pm 5.5)$ & $51.0(1,5,0)$ & 24.9 & 0.5 & 6.7 & 41,5 & 48.2 & 41.5 & 40,4 & 40.7 \\
\hline Sample 3 & $46.5( \pm 4.0)$ & $51.3( \pm 5,5)$ & $38 ; 0 ;-150)$ & $47.7( \pm 4.5)$ & 62.9 & 2.7 & $2 \overline{6}, 1$ & 40.5 & 56.7 & 51.9 & 43.1 & 43.4 \\
\hline Sample 4 & $66.6( \pm 3.5)$ & $51.6(+3.0)$ & $32,5[13.5]$ & $44.0( \pm 4.0)$ & 24.0 & 0.8 & 8.8 & 43.1 & 51.9 & 43.1 & 41.1 & 41,3 \\
\hline Sample 5 & $53.2( \pm 4.0)$ & $34.8( \pm 5.5)$ & $33.5[ \pm 2.5]$ & $32.4( \pm 4.0)$ & 17.6 & 0.0 & 1.9 & 42.7 & 44.6 & 49.3 & 44.7 & 44.9 \\
\hline Sample 6 & $68.7( \pm 3.0)$ & $40.4( \pm 4.0)$ & $37,0( \pm 4,0)$ & $47.1( \pm 5.5)$ & 13.2 & 0.1 & 2.0 & 41,0 & 43.0 & 41.0 & $4 t .1$ & 41.4 \\
\hline
\end{tabular}

a Surface free energy value according to Wu equation of state [36]. b Surface free energy value according to Kwok-Neumann model [36]. c Surface free energy value according to Li-Neumann model [36].

upon incubation in water for $24 \mathrm{~h}$ are found to be more hygroscopic compared to the pristine sample which shows a minimal uptake. Sample 5 shows a remarkably high water uptake after $24 \mathrm{~h}$ probably corresponding to distinctive surface attributes to be further discussed later. The corresponding surface densities of the absorbed water (mass of water/surface area) after subtraction from the control sample are displayed as an inset in Fig. 4 which correlate with the surface wettability. It may be utilized to provide some insight into the level of surface modifications.

\subsection{Surface morphology analysis}

Micrographs of the examined samples before and after multistep modifications are presented in Fig. 5. A relatively smooth, uniform morphology is observed for sample 1 which undergoes a significant alteration as a result of the DCSBD plasma treatment (sample 2) showing an etched character with an irregular shaped texture. This new morphology is advantageous for following coupling processes due to an increased surface area and roughness [5]. In fact, the generated pattern on the sample 2 surface is a consequence of competition between functionalization and ablation phenomena both leading to surface restructuring [8]. The occurrence of ablation is ascertained via gravimetric means where a weight loss of $\wedge 4$ fjugcm ${ }^{-2}$ has been observed due to the plasma treatment for $15 \mathrm{~s}$ implying an etching rate of $\sim 2 \mathrm{~nm} / \mathrm{s}$ taking into account the density of the PVC grade used. According to the micrograph of sample 3 after chemical grafting, PAA chains form their

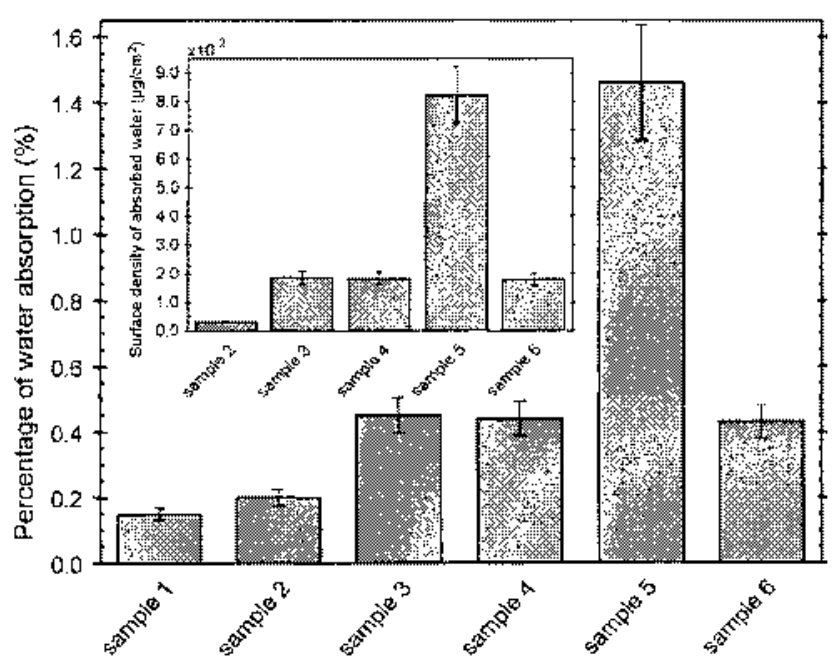

Fig. 4. Percentage of water absorption after $24 \mathrm{~h}$ for samples 1-6. The inset shows the corresponding surface density of absorbed water (the error bars depict standard deviations). own submicron domains and ripple-like features are discernible on the surface. A factor contributing to the surface microstructure is the mechanism of the grafting, which is initiated by radicals generated on the surface. Some of the radicals may also be present below the top layer and initiate the grafting reaction. This brings about an apparently swelled grafted top layer following the diffusion of monomers and participation in chain propagation [41]. Indeed, the roughest morphology is observed for sample $3 \mathrm{com}$ pared to the others showing a brush-like pattern which forms an active support for subsequent modifications. Similar finding was reported on AA-grafted polyurethane [42]. Quantitatively, based on the gravimetric data, the average graft density of PAA, assuming uniform distribution, is estimated to be " 185 |jigcm $^{-2}$, which is higher than the average values attained in similar works devoted to surface grafting of PAA $[41,43,44]$. Interestingly, the estimated graft density is on the order of the surface absorbed water density of sample 3 assessed in the former section. Regarding the approximate PAA homopolymer density, $1.1 \mathrm{gem}^{-3}[41]$, the grafted brush dry thickness should be on the order of $1.5 \mid \mathrm{xm}$. As presented in Fig. 5, an almost smooth and uniform morphology is found for samples 4 and 5 . As for sample 6 , a rough morphology is observed likely due to artifacts induced by electron irradiation.

\subsection{Surface chemistry analysis}

On the basis of the literature [45], the average sampling depth of ATR-FTIR probe equipped with ZnSe crystal for a polymer having a refractive index of " 1.5 , like PVC, is " $4 \mid$ jim which exceeds the normal thickness of modified layers on a substrate. Nonetheless, ATR-FTIR is still widely used to provide semiquantitative information on the chemistry of the near-surface region. The infrared spectra of samples 1-6 split over three different wavenumber ranges for the sake of clarity are illustrated in Fig. 6. The major characteristic bands of ester, and carbonylcontaining groups are observed in the spectrum of sample 1 in addition to pure PVC characteristic signals which is indicative of several additives existing in the current medical-grade PVC. Upon exposure to DCSBD plasma, no significant change is detected regarding the sample 2 spectrum, compared to sample 1 . This is not only because of signals overlapping, but also due to the plasma modification depth being limited to solely top layers of the surface and cannot be well evidenced by ATR-FTIR. However a new peak of weak intensity appears around $1630 \mathrm{~cm}^{-1}$ assigned to $\mathrm{C}=\mathrm{C}$ stretching mode as a consequence of the ablation (dehydrochlorination) process [46]. Based on the sample 3 spectrum, a very broad but weak peak appears in the range of $3000-3400 \mathrm{~cm}^{-1}$ corresponding to $\mathrm{H}$-bonded $-\mathrm{OH}$ stretching mode in carboxylic acids. C-H stretching bands within $2800-3000 \mathrm{~cm}^{-1}$ gain height. The characteristic $\mathrm{C}=0$ stretching band around 1720 $\mathrm{cm}^{-1}$ is raised in magnitude. The peaks appearing within 1400$1500 \mathrm{~cm}^{-1}$ assigned to $\mathrm{CH} 2$ vibra 


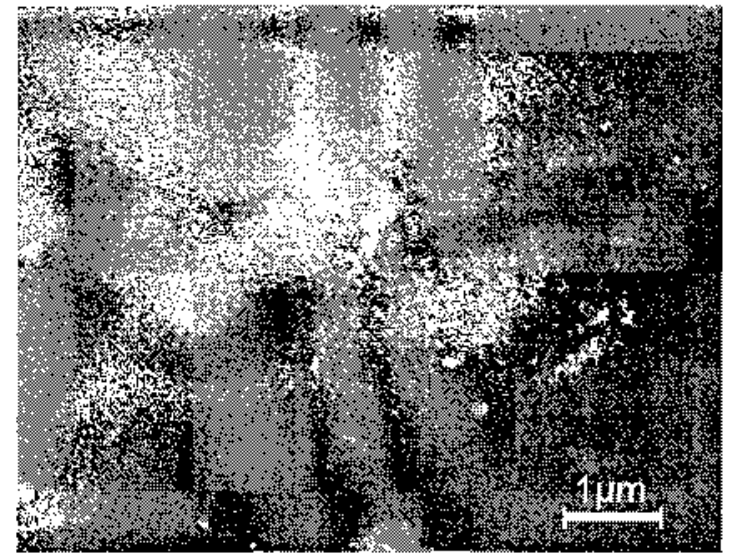

sample ]

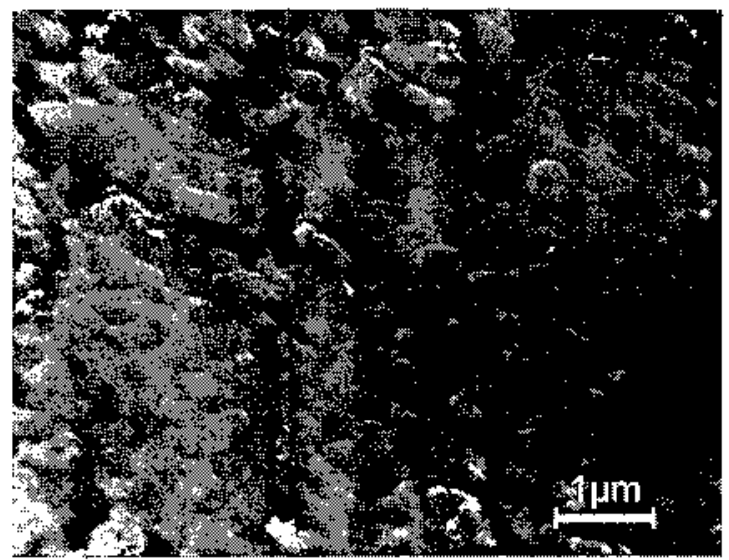

sample 3

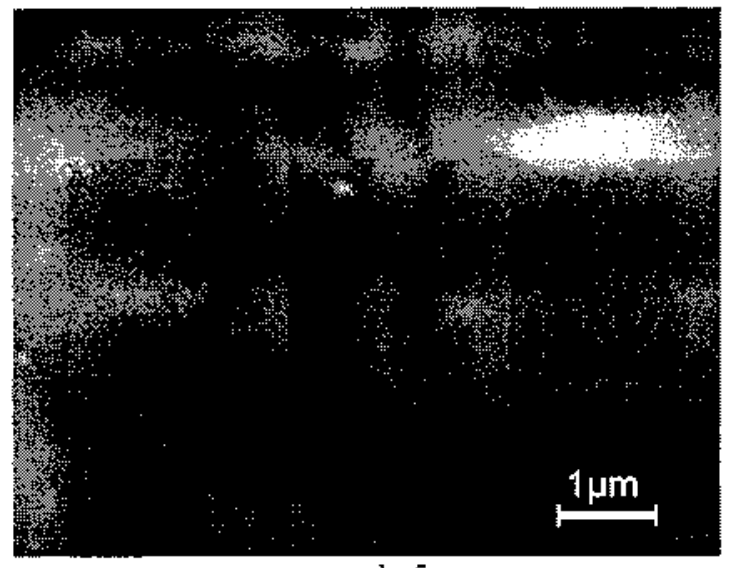

sample 5

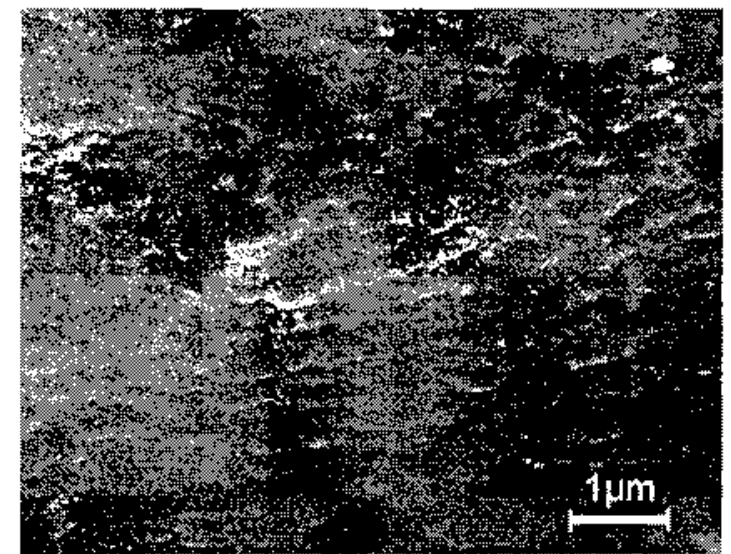

sample 2

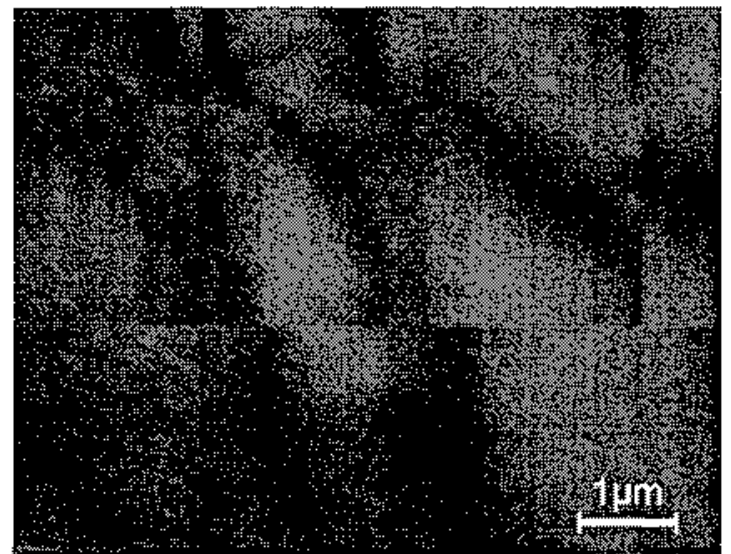

sample 4

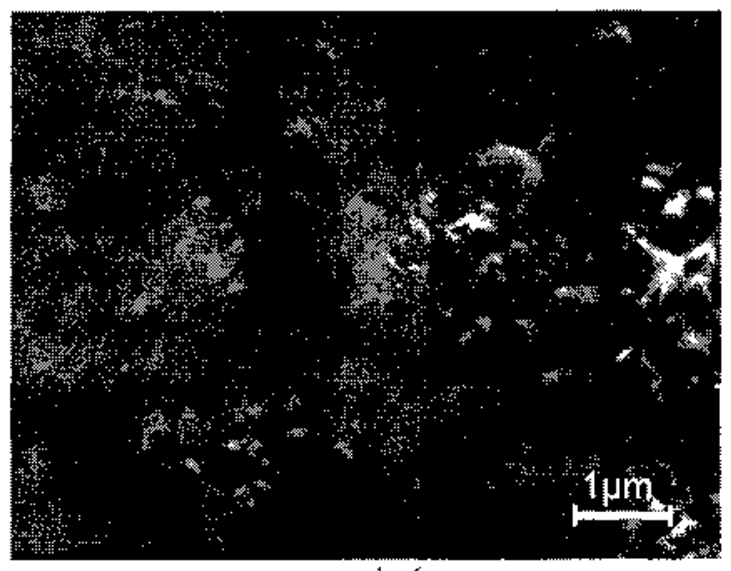

sample 6

Fig. 5. SEM micrographs of samples 1-6 taken at $30000 \times$ magnification.

tion, $\mathrm{CH}_{3}$ deformation, and $-\mathrm{OH}$ bending modes slightly increase in intensity, so do the signals within $1100-1300 \mathrm{~cm}^{-1}$ corresponding to $\mathrm{C}-0$ stretching vibration in carboxylic compounds as well as $\mathrm{CH} 2$ bending. The peaks within $600-700 \mathrm{~cm}^{-1}$ associated with $\mathrm{C}-\mathrm{Cl}$ bond stretching attenuate. The stated alterations lend support to the coupling of PAA units onto the surface. No significant changes emerge as benzalkonium chloride is coated on the surface (sample 4). The intensity and breadth of $1720 \mathrm{~cm}^{-1}$ band due to $\mathrm{C}=0$ stretch reduces and slightly shifts down to a lower wavenum- ber. Weak peaks within 1515-1565 $\mathrm{cm}^{-1}$ associated with $\mathrm{C}=0-0 \sim$ in carboxylic salts disappear. The peak at $1480 \mathrm{~cm}^{-1}$ assigned to
$\mathrm{CH}_{2}$ vibration in aliphatic compounds abates, so does the signal at $1190 \mathrm{~cm}^{-1}$ corresponding to $\mathrm{C}-0$ stretching vibration in carboxylic compounds. Also, the peaks within $550-580 \mathrm{~cm}^{-1}$ assigned to C$\mathrm{C}=0$ bending mode attenuate. As for sample 5 which is coated with bronopol, a very broad peak emerges over $3200-3600 \mathrm{~cm}^{-1}$ ascribed to $-\mathrm{OH}$ stretching vibration in alcohols. The absorption bands within 2800-3000 $\mathrm{cm}^{-1}$ corresponding to $\mathrm{C}-\mathrm{H}$ bond stretching mode of aliphatic compounds decreases in strength. The major peak of $\mathrm{C}=0$ group at $1720 \mathrm{~cm}^{-1}$ abates. The intensity of peaks of 1580 and $1600 \mathrm{~cm}^{-1}$ assigned to $\mathrm{C}=0-0 \sim$ anion stretching vibration in carboxylic salts decreases. A new weak sig 

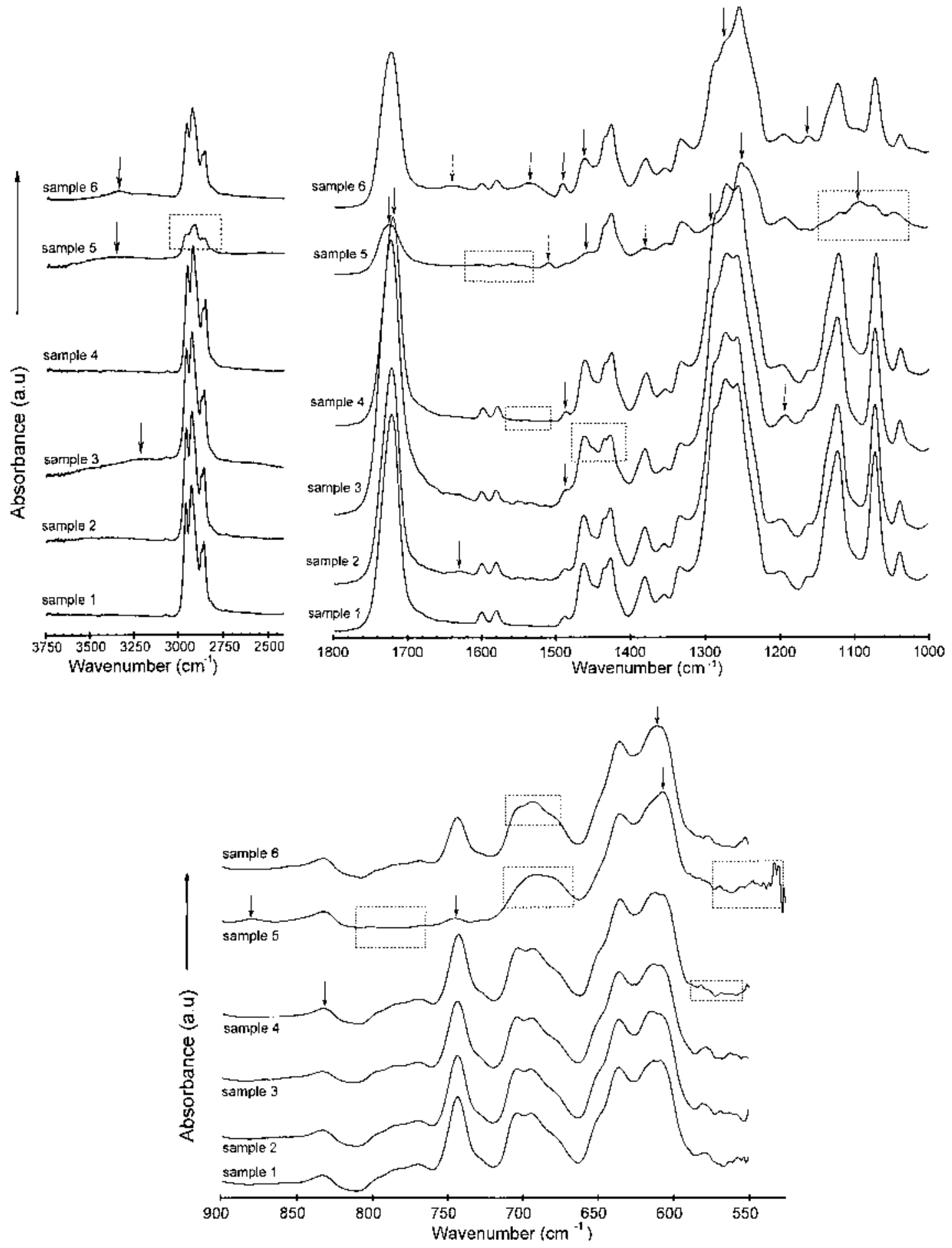

Fig. 6. ATR-FTIR spectra of samples 1-6 split over three wavenumber ranges.

nal comes into view at $1520 \mathrm{~cm}^{-1}$ associated with $\mathrm{NO}_{2}$ stretching mode. The intensity of peaks over $1400-1480 \mathrm{~cm}^{-1}$ corresponding to $-\mathrm{OH}$ bending in carboxylic acids and $\mathrm{CH} 2$ vibration in aliphatic compounds diminishes. A signal at $1380 \mathrm{~cm}^{-1}$ related to $\mathrm{CH}_{3}$ in aliphatic compounds as well as $\mathrm{C}=0-0 \sim$ anion stretching vibration loses strength while the peak near $1340 \mathrm{~cm}^{-1}$ intensifies which is characteristic of $\mathrm{NO} 2$ stretching deformation. A new peak arises at $1090 \mathrm{~cm}^{-1}$ assigned to $\mathrm{C}-0$ stretching absorption in alcohols. Three peaks at 1040,1070 , and $1150 \mathrm{~cm}^{-1}$ corresponding to $\mathrm{C}-\mathrm{O}-\mathrm{C}$ stretching mode in esters abate in strength, so do the bands over $1220-1320 \mathrm{~cm}^{-1}$. A new absorption at $870 \mathrm{~cm}^{-1}$ appears which may be related to $\mathrm{C}-\mathrm{N}$ stretching mode in nitro compounds. The signals within 700-800 $\mathrm{cm}^{-1}$ assigned to $\mathrm{C}-\mathrm{Cl}$ stretching mode of $\mathrm{PVC}$ and $\mathrm{CH}$ deformation in substituted benzenes weaken in intensity. A sharp peak around $540 \mathrm{~cm}^{-1}$ corresponding to $\mathrm{C}-\mathrm{Br}$ stretch band emerges. Regarding the spectrum of sample 6 (coated with chlorhexidine) a new broad peak at $3330 \mathrm{~cm}^{-1}$ arises corresponding to $\mathrm{N}-\mathrm{H}$ stretching mode in secondary amines. The intensity of 

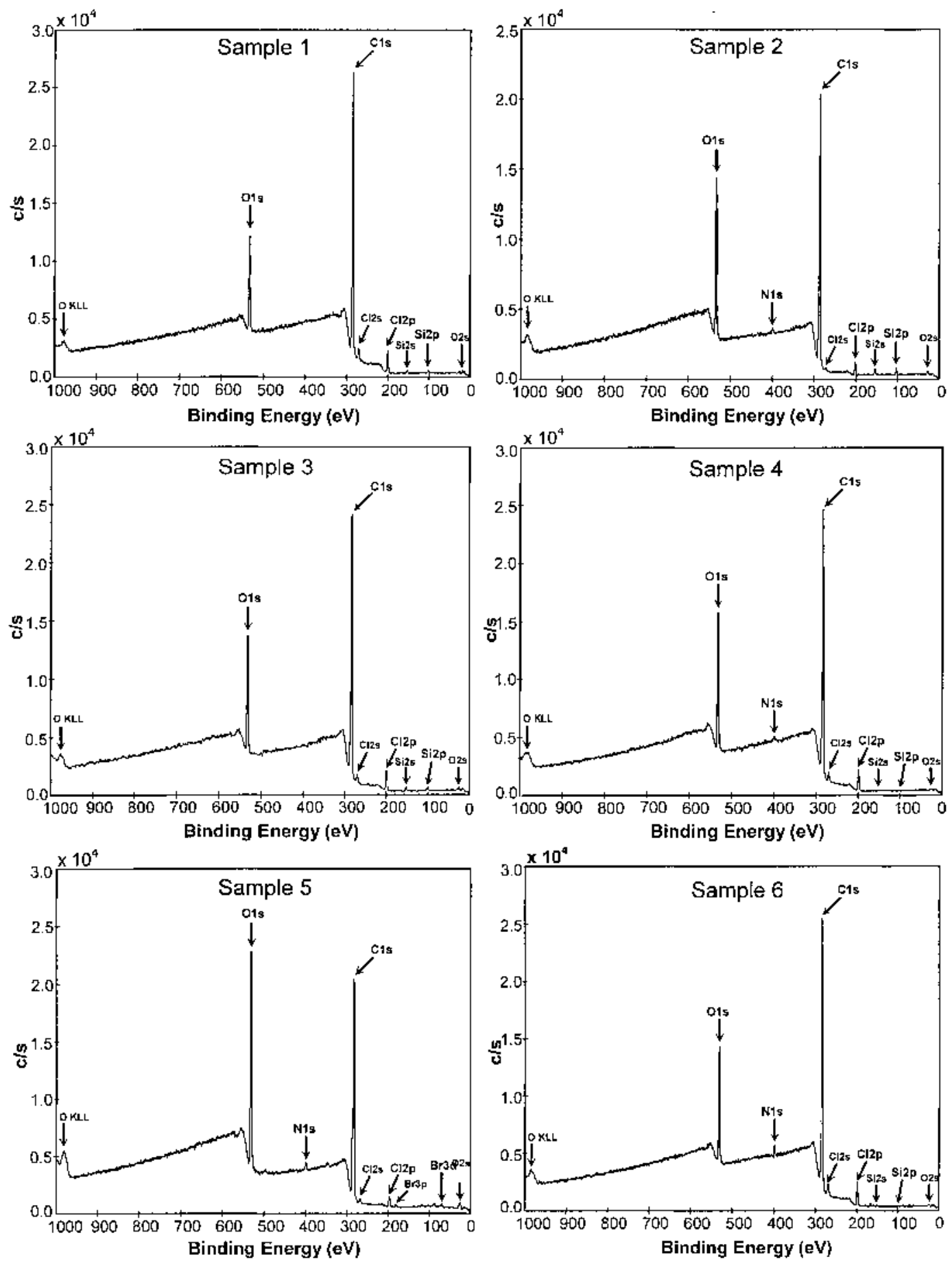

Fig. 7. XPS survey-scan spectra of samples 1-6.

signals over $2800-3000 \mathrm{~cm}^{-1}$ corresponding to $\mathrm{C}-\mathrm{H}$ bond stretching mode of aliphatic compounds reduces. The major $\mathrm{C}=0$ signal intensity at $1720 \mathrm{~cm}^{-1}$ decreases. New broad peaks at $1640 \mathrm{~cm}^{-1}$ corresponding to $\mathrm{C}=\mathrm{N}$ vibration and $1530 \mathrm{~cm}^{-1}$ due to aromatic ring stretching appear. The intensity of peak around $1480 \mathrm{~cm}^{-1}$ corresponding to $-\mathrm{OH}$ bending in carboxylic acids and $\mathrm{CH}_{2}$ vibration in aliphatic compounds diminishes. Three peaks at 1040,1070, and $1150 \mathrm{~cm}^{-1}$ corresponding to $\mathrm{C}-\mathrm{O}-\mathrm{C}$ stretching mode in esters abate in strength, so do the bands over $1220-1320 \mathrm{~cm}^{-1}$. The intensity of a peak around $600 \mathrm{~cm}^{-1}$ corresponding to $\mathrm{C}-\mathrm{Cl}$ bond absorption in aromatic compounds increases. The aforesaid alterations in IR spectra of samples 4-6 give credence to the presence of the antibacterial agents on the surface.

To further examine the impact of multistep surface modifications, XPS is employed to gain a quantitative insight into the elemental composition of the surface with a probe depth on the order of $5 \mathrm{~nm}$ [47]. The acquired survey spectra and the corresponding surface atomic compositions and ratios of samples 1 -6 are given in Fig. 7 and Table 2, respectively. The preliminary analysis of sample 1 indicates the presence of carbon (C), oxygen (O), chlorine $(\mathrm{Cl})$, 
Table 2

\begin{tabular}{|c|c|c|c|c|c|c|c|c|c|c|}
\hline specimen & {$\left[1 s\left(y^{\prime}\right)\right.$} & $015(8)$ & N1s [s] & $(12 \mathrm{p}(\mathrm{s})$ & $5 \mathrm{i} 2 \mathrm{p}\left(\mu_{2}\right)$ & $B: 3 d(\gamma)$ & $0, C$ & $\mathrm{~N} / \mathrm{C}$ & $C_{f j} \mathrm{C}$ & $5 i / c$ \\
\hline Sample 1 & $83.5( \pm 2,0)$ & $125(+1,04)$ & - & $2.7( \pm 0.5)$ & $1,3(1-0,3)$ & - & 0.149 & - & 0,032 & 0.016 \\
\hline Sampie 2 & $74.8( \pm 0.6)$ & $19.5(-10.5)$ & $1.0(10.4)$ & $2.5( \pm 0.5)$ & $2.1\{ \pm 0.2\}$ & - & 0.261 & 0.013 & 0.035 & 0.028 \\
\hline Sample 3 & $79.9(10.9)$ & $16.3(+0.2)$ & - & $2.5( \pm 0.2)$ & $1.3(4.5 .5)$ & - & 0,204 & - & 0,030 & 0.016 \\
\hline Sample 4 & $78.7(.0 .6)$ & $18.0(10.2)$ & $0.4(1.0 .1)$ & $2.5[40.3)$ & $0.4( \pm 0.0)$ & - & 0.229 & 0.005 & 0.003 & 0.005 \\
\hline 5 & $69.1(-1,5)$ & $25.7(-1.2,0)$ & $1.5(1.0,1)$ & $3, n(4,0,4)$ & . & $0,3(-1.0,1)$ & 0,372 & 0,026 & 0.043 & - \\
\hline Sample 6 & $79.8(1,0.1)$ & $14.8( \pm 0.5)$ & $2.1( \pm 0.2)$ & $3.1[ \pm 0.3)$ & $0.1( \pm 0.0)$ & $\rightarrow$ & 0.185 & 0.026 & 0.039 & 0.001 \\
\hline
\end{tabular}

and silicon (Si) elements whose composition and elemental ratios are presented in Table 2. Based on the data, the $\mathrm{C} 12 \mathrm{p}$ atomic content is significantly lower than expected for a standard PVC containing no additives originating from the presence of several additives and also X-ray degradation [48]. Due to the same reason, a considerable amount of Ols is detected on the sample 1 surface which is not a typical element found in standard PVC. This verifies the ATR-FTIR results. Finally, XPS discerns traces of silicon on the sample 1 surface, which most likely appear because of the production/moulding process as a contaminant. Apparent alterations in $\mathrm{Cls}, \mathrm{Ols}$, and $\mathrm{C} 12 \mathrm{p}$ core-level signals intensity arise for sample 2 quantitatively indicated in Table 2 . The $\mathrm{C} 12 \mathrm{p}$ content decreases and Ols content considerably increases. Thus, ablation leads to introduction of oxygen-containing entities and also dehydrochlorination. Furthermore, nitrogen element (N1s) is detected on the surface as a consequence of the air plasma treatment. It shows that the DCSBD plasma treatment for $15 \mathrm{~s}$ markedly influences the surface elemental composition. The modification is also reflected in $\mathrm{O} / \mathrm{C}$ and $\mathrm{Cl} / \mathrm{C}$ ratios when compared to those of sample 1. The former rises while the latter diminishes appreciably. Surprisingly, the amount of Si2p on the surface increases which may come from plasma parts as a contaminant. Upon PAA grafting, the $01 \mathrm{~s}$ quantity compared to the plasma treated decreases, however, when compared to sample 1, it increases. Although, an Ols content higher than plasma treated was expected for sample 3 since a pure PAA surface would yield an oxygen atomic concentration of $\wedge 40 \%$, according to the literature [41 ]. This suggests that the PAA chains may be distributed not only on the surface but also in the subsurface layers extending well beneath the XPS probe depth. The $\mathrm{C} 12 \mathrm{p}$ content shows no change upon PAA grafting. Besides, nitrogen is no longer detectable on the sample 3 surface. However, the Si2p signal abates due to the surface coverage. All atomic content ratios decrease for sample 3, when compared to sample 2. Nitrogen band (Nls) emerges in the spectra as three nitrogen-containing antibacterial agents are coated onto the surface (samples 4-6), among which the maximum belongs to chlorhexidine as expected. The $\mathrm{C} 12 \mathrm{p}$ content increases as bronopol and chlorhexidine are coated onto the surface. Also, bromine is detected as $\mathrm{Br} 3 \mathrm{~d}$ in the case of sample 5 which ensures the immobilization of bronopol. Sample 5 shows a high content of Ols which seems to be the reason behind unusual hygroscopic behavior examined in an earlier section. The maximum atomic ratios of $\mathrm{O} / \mathrm{C}$ and $\mathrm{Cl} / \mathrm{C}$ are exhibited by the bronopol coated sample. The Si2p content decreases in samples 4-6. The XPS analysis manifestly supports the presence of three antibacterial agents on the surface, however, this is more substantial for chlorhexidine and bronopol than benzalkonium chloride. The role of glutaraldehyde as a fixative for chlorhexidine immobilization cannot be disregarded.

\subsection{Bacterial adhesion and biofilm assay}

Bacterial adhesion, the pivotal stage of biofilm formation, is an elaborate topic whose many aspects to date have not been well understood in which numerous physicochemical factors are involved [49]. The bacterial adhesion degree for samples 1-6 after $24 \mathrm{~h}$ incubation is presented as histograms in Fig. 8. However, the but the results are evaluated herein after $24 \mathrm{~h}$ incubation for a better assessment of the biofilm formation. Regarding the adherence degree of $S$. aureus onto the samples, no decrease is observed in the number of viable colonies adhered onto the surface of samples 2-5 compared to the sample 1 implying the inefficiency of the modifications in reducing the adherence of $S$. aureus onto the surface. However, a $50 \%$ inhibition is observed for sample 6 suggesting the capability of chlorhexidine in hampering adhesion of gram-positive strain. Two capital factors seem determining in the observed adhesion degree trend, viz., wettability and surface topography. The adhesion degree is found to correlate with the hydrophilicity and roughness of the samples. For samples 1-3, an increase in hydrophilicity and roughness was remarked as previously proved and then a decrease was observed in the case of
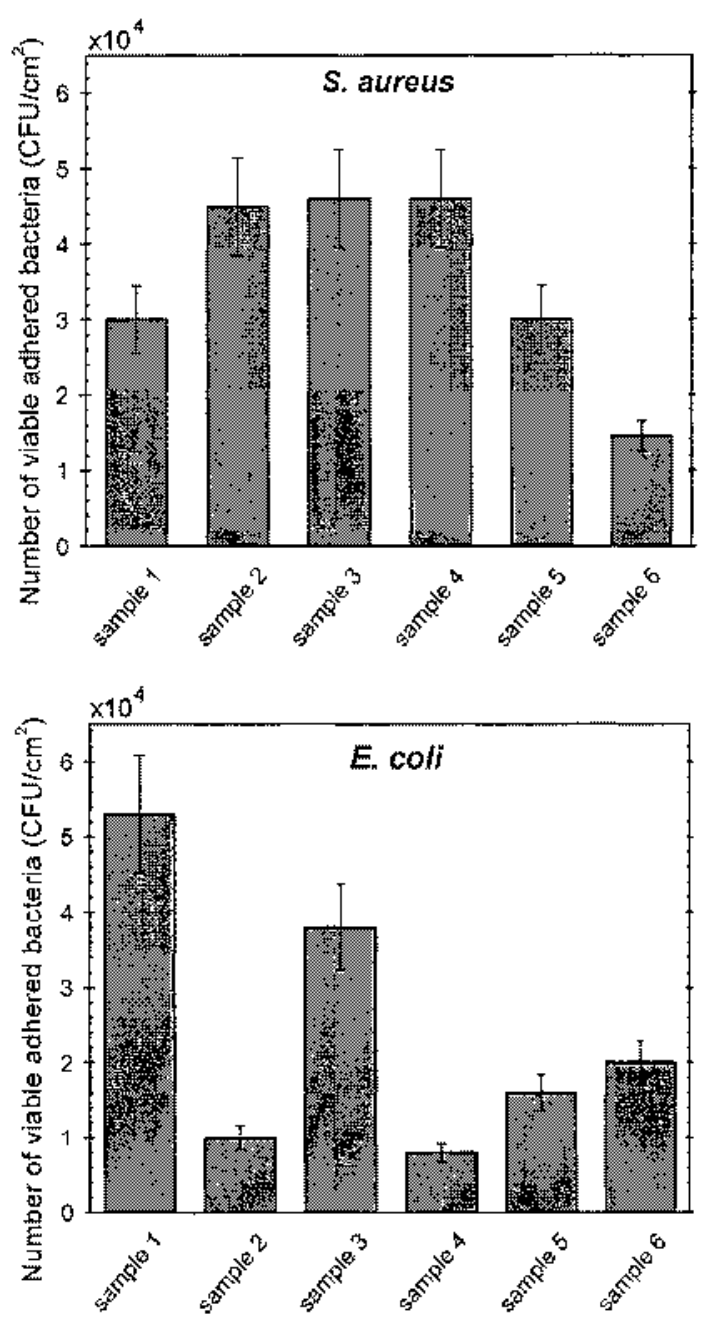

Fig. 8. Histograms of bacterial adhesion degree for samples 1-6 after $24 \mathrm{~h}$ incubation against two microorganisms (the error bars depict standard deviations). 
samples 4 and 5 . The variation of adhesion degrees also follows alike. Considering sample 6 , it is inferred that chlorhexidine imparts biocidal effects against 5. aureus. As for the E. coli adherence, the scenario looks different as it shows more susceptibility towards modifications. Samples 2-6 notably outperform sample 1 against bacterial adhesion. The plasma treatment is able to hamper the bacterial adhesion up to $80 \%$, where the graft copolymerization of PAA reduces the adherence degree by $30 \%$. Benzalkonium chloride, bronopol, and chlorhexidine restrain the adherence degree by $85 \%, 70 \%$, and $60 \%$, respectively. It is realized that among the three antibacterial agents used, benzalkonium chloride acts best against the gramnegative bacterial adhesion, while chlorhexidine is effective against both strains. The different bacterial behavior on the samples reflects the complex surface structure and motility of $E$. coli compared to $S$. aureus as described elsewhere [50]. Also, the number of $£$ coli adhered onto sample 1 is higher than that of adhered $S$. aureus mainly due to the difference between the physicochemical characteristics of the bacteria and materials [49]. Indeed, gramnegative $E$. coli has flagella on the structures external to the cell wall and so, has mobility. Furthermore, E. coli has fimbriae which make the bacterium more adsorbable. Therefore, the multistep modifications are more effective to $E$. coli than $S$. aureus $[51,52]$. Based on our results, the antibacterial samples do not fully inhibit the formation of the bacterial biofilm after $24 \mathrm{~h}$ incubation in a high cell concentration suspension which is in accord with a report from Zhang et al. [25]. Further investigations are essential as yet to shed more light on interaction of living microorganisms and biomaterials surfaces and its relevance to physicochemical characteristics.

\section{Conclusions}

The adopted multistep physicochemical approach manifests itself as a promising strategy to regulate the anti-adherence properties of medical-grade PVC surface by curbing the adhesion of pathogenic bacteria. Benzalkonium chloride performs prominently by hampering $E$. coli adhesion by $85 \%$, while it is unable to perform effectively against S. aureus. Bronopol similarly functions against $E$. coli $(75 \%$ reduction) and $S$. aureus (no reduction). Chlorhexidine is found to be effective against both gram-positive and negative strains which decreases the adherence degree of the former by $50 \%$ and the latter by $60 \%$. Furthermore, plasma treated and graft copolymerized samples are effective in diminishing the adherence of gram-negative strain. The $E$. coli adhesion course is found to be more vulnerable to the modifications and the employed antibacterial agents. The findings of this contribution are expected to be of merit not only from the applied standpoint as far as the indwelling medical implants are concerned, but also from the scientific viewpoint for it lies in the interface of the polymer surface science and

\section{Acknowledgements}

Financing this research by the Ministry of Education, Youth, and Sports of the Czech Republic (Grant VZ MSM 7088352101) as well as Ministry of Industry and Trade of the Czech Republic (Grant MPO 2A-1TP1/126), the Slovak Academy of Sciences (Grant VEGA 2/7103/27), and the Slovenia Ministry of Higher Education, Science, and Technology (Program P2-0082-2, Thin Film Structures and Plasma Surface Engineering) is appreciated.

\section{References}

[1] G. Speranza, G. Gottardi, C. Pederzolli, L. Lunelli, R. Canteri, L. Pasquardini, E. Carli, A. Lui, D. Maniglio, M. Brugnara, M. Anderle, Role of chemical interactions in bacterial adhesion to polymer surfaces, Biomaterials 25 (2004) 2029-2037.

[2] K. Triandafillu, D.J. Balazs, B.O. Aronsson, P. Descouts, P.T. Quo, C. van Delden, H.J. Mathieu, H. Harms, Adhesion of Pseudomonas aeruginosa strains to untreated and oxygen-plasma treated poly(vinyl chloride) (PVC) from endotracheal incubation devices, Biomaterials 24 (2003) 1507-1518.

[3] N.R. James, J.A. Jayakrishnan, Surface thiocyanation of plasticized poly(vinyl chloride) and its effect on bacterial adhesion, Biomaterials 24 (2003) 2205-2212.

[4] E.R. Kenawy, S.D. Worley, R. Broughton, The chemistry and applications of antimicrobial polymers: a state-of-the-art review, Biomacromolecules 8 (2007) 13591384

[5] P.K. Chu, J.Y. Chen, L.P. Wang, N. Huang, Plasma-surface modification of biomaterials, Mater. Sei. Eng. R36 (2002) 143-206.

[6] K.M. McGinty, W.J. Brittain, Hydrophilic surface modification of poly( vinyl chloride) film and tubing using physisorbed free radical grafting technique, Polymer 49 (2008)4350-4357.

[7] M.W. Huh, I.K. Kang, D.H. Lee, W.S. Kim, D.H. Lee, L.S. Park, ICE. Min, K.H. Seo, Surface characterization and antibacterial activity of chitosan-grafted poly(ethylene terephthalate) prepared by plasma glow discharge, J. Appl. Polym. Sei. 81 (2001) 27692778.

[8] A. Vesel, I. Junkar, U. Cvelbar, J. Kováč, M. Mozetič, Surface modification of polyester by oxygen- and nitrogen-plasma treatment, Surf. Interface Anal. (40) (2008) 14441453

[9] A. Vesel, M. Mozetič, M. Zalar, XPS characterization of PTFE after treatment with RF oxygen and nitrogen plasma, Surf. Interface Anal. 40 (2008) 661-663.

[10] M. Černák, L. Černáková, I. Hudec, D. Kováčik, A. Zahoranová, Diffuse coplanar surface barrier discharge and its applications for in-line processing of low- added-value materials, Eur. Phys. J.: Appl. Phys. 47 (2009), 22806pl-22806p6.

[11] M. Šimor, J. Ráhel, P. Vojtek, M. černák, Atmospheric-pressure diffuse coplanar surface discharge for surface treatments, Appl. Phys. Lett. 81 (2002) 2716-2718.

[12] L. Bónová, A. Buček, T. Plecenik, A. Zahoranová, M. Černák, Cleaning of aluminium surface using diffuse coplanar surface barrier discharge, Chem. Listy 102(2008)14521454.

[13] L. Černáková, R. Szabová, M. Wolfová, A. Buček, M. Černák, Surface modification of polypropylene nonwoven after plasma activation at atmospheric pressure, Fibers Text. East. Eur. 15 (2007) 64-65

[14] A. Bhattacharyaa, B.N. Misra, Grafting: a versatile means to modify polymers. Techniques, factors and applications, Prog. Polym. Sei. 29 (2004) 767-814.

[15] B. Zhao, W.J. Brittain, Polymer brushes: surface-immobilized macromolecules, Prog. Polym. Sei. 25 (2000) 677-710

[16] Y. Uyama, K. Kato, Y. Ikada, Surface modification of polymers by grafting, Adv. Polym. Sei. 137(1998)1-39.

[17] S. Tripathi, G.K. Mehrotra, P.K. Dutta, Chitosan based antimicrobial films for food packaging applications, e-Polymers 093 (2008).

[18] T.S.J. Elliott, S.E. Tebbs, Prevention of central venous catheter-related infection, J. Hosp. Infect. 40 (1998) 193-201.

[19] Z.L. Shi, K.G. Neoh, S.P. Zhong, L.Y.L. Yung, E.Y. Kang, W. Wang, In vitro antibacterial and cytotoxicity assay of multilayered polyelectrolyte-functionalized stainless steel, J. Biomed. Mater. Res.: Part A 76 (2006) 826-834.

[20] D.M. Bryce, B. Croshaw, J.E. Hall, V.R. Holland, B. Lessel, The activity and safety of the antimicrobial agent bronopol (2-bromo-2-nitropropan-1,3-dioI), J. Soc. Cosmet. Chem. 29 (1978) 3-24.

[21] W. Zhang, P.K. Chu, J.Ji, Y. Zhang, R.K.Y. Fu, Q. Yan, Antibacterial properties of plasma-modified and triclosan or bronopol coated polyethylene, Polymer 47 (2006)931936.

[22] A.D. Russell, F.R.C. Path, Chlorhexidine-antibacterial action and bacterial resistance, Infection 14 (1986) 212-215.

[23] S. Jenkins, M. Addy, W. Wade, The mechanism of action of Chlorhexidine, J. Clin. Periodontol. 15 (1987) 415-424

[24] W. Zhang, P.K. Chu, J. Ji, Y. Zhang, X. Liu, R.K.Y. Fu, P.C.T. Ha, Q. Yan, Plasma surface modification of poly vinyl chloride for improvement of antibacterial properties, Biomaterials 27 (2006) 44-51.

[25] W. Zhang, P.K. Chu,J.Ji, Y. Zhang, S.C. Ng, Q. Yan, Surface antibacterial characteristics of plasma-modified polyethylene, Biopolymers 83 (2006) 62-68.

[26] J.C. Harnet, E.L. Guen, V. Ball, H. Tenenbaum, J. Ogier, Y. Haikel, C. Vodouhé, Antibacterial protection of suture material by chlorhexidine-functionalized polyelectrolyte films, J. Mater. Sei.: Mater. Med. 20 (2009) 185-193.

[27] D. Adams, M. Quayum, T. Worthington, P. Lambert, T. Elliott, Evaluation of a $2 \%$ chlorhexidine gluconate in $70 \%$ isopropyl alcohol skin disinfectant, J. Hosp. Infect. 61 (2005)287-290.

[28] C. Yao, X. Li, ICG. Neoh, Z. Shi, E.T. Kang, Surface modification and antibacterial activity of electrospun polyurethane fibrous membranes with quaternary ammonium moieties, J. Membr. Sei. 320 (2008) 259-267.

[29] J. Thome, A. Holländer, W. Jaeger, I. Trick, C. Oehr, Ultrathin antibacterial polyammonium coatings on polymer surfaces, Surf. Coat. Technol. 174 (2003) 584587.

[30] Y.J. Kim, I.IC Kang, M.W. Huh, S.C. Yoon, Surface characterization and in vitro blood compatibility of poly(ethylene terephthalate) immobilized with insulin and/or heparin using plasma glow discharge, Biomaterials 21 (2000) 121-130.

[31] N. Nakajima, Y. Ikada, Mechanism of amide formation by carbodiimide for bioconjugation in aqueous-media, Bioconjug. Chem. 6 (1995) 123-130.

[32] F.A. Carey, R.J. Sundberg, Advanced Organic Chemistry. Part B: Reactions and Synthesis, Springer, New York, 2007.

[33] F.S. Denes, S. Manolache, Macromolecular plasma-chemistry: an emerging field of polymer science, Prog. Polym. Sei. 29 (2004) 815-885.

[34] M. Lehocký, H. Drnovská, B. Lapčíková, A.M. Barros-Timmons, T. Trindade, M. Zembala, L. Lapčik, Plasma surface modification of polyethylene, Colloids Surf. A 222(2003) 125-131. 
[35] I. Novák, V. Pollák, I. Chodák, Study of surface properties of polyolefins modified by corona discharge plasma, Plasma Process. Polym. 3 (2006) 355-364.

[36] P.K. Sharma, K.H. Rao, Analysis of different approaches for evaluation of surface energy of microbial cells by contact angle goniometry, Adv. Colloid Interface Sci. 98 (2002)341-463.

[37] B. Jančzuk, T. Biatopiotrowicz, A. Zdziennicka, Some remarks on the components of the liquid surface free energy, J. Colloid Interface Sci. 211 (1999) 96-103.

[38] M.R. Yang, K.S. Chen, J.C. Tsai, C.C. Tseng, S.F. Lin, The antibacterial activities of hydrophilic-modified nonwoven PET, Mater. Sci. Eng. C 20 (2002) 167-173.

[39] K.S. Chen, Y.A. Ku, H.R. Lin, T.R. Yan, D.C. Sheu, T.M. Chen, Surface grafting polymerization of $\mathrm{N}$-vinyl-2-pyrrolidone onto a poly(ethylene terephthalate) nonwoven by plasma pretreatment and its antibacterial activities, J. Appl. Polym. Sci. 100 (2006) by plasma

[40] M.Z. Elsabee, S.A. Entsar, S.A. Khaled, Surface modification of polypropylene films by chitosan and chitosan/pectin multilayer, Carbohydr. Polym. 71 (2008) 187-195.

[41] B. Gupta, C. Plummer, I. Bisson, P. Frey, J. Hilborn, Plasma-induced graf polymerization of acrylic acid onto poly( ethylene terephthalate) films: characterization polymerization of acrylic acid onto poly( ethylene terephthalate) films: characterization
and human smooth muscle cell growth on grafted films, Biomaterials 23 (2002)863871.

[42] S. Sartori, A. Rechichi, G. Vozzi, M. D’Acunto, E. Heine, P. Giusti, G. Ciardelli, Surface modification of a synthetic polyurethane by plasma glow discharge: preparation and characterization of bioactive monolayers, React. Funct. Polym. 68(2008)809-821.
[43] B. Gupta, S. Saxena, A. Ray, Plasma induced graft polymerization of acrylic acid onto polypropylene monofilament, J. Appl. Polym. Sci. 10 (2008) 324-330

[44] M.C. Yang, W.C. Lin, The grafting of chitosan oligomer to polysulfone membrane via ozone-treatment and its effect on anti-bacterial activity, J. Polym. Res. 9 (2002) 135140 .

[45] B. Stuart, Infrared Spectroscopy: Fundamentals and Applications, Wiley, New York, 2004.

[46] H. Kumagai, T. Tashiro, T. Kobayashi, Formation of conjugated carbon bonds on poly(vinyl chloride) films by microwave-discharge oxygen-plasma treatments, J. Appl. Polym. Sci. 96 (2005) 589-594

[47] C.M. Chan, Polymer Surface Modification and Characterization, Hanser Gardner, Cincinnati, 1994.

[48] D.J. Balazs, K. Triandafillu, Y. Chevolot, B.O. Aronsson, H. Harms, P. Descouts, H.J. Mathieu, Surface modification of PVC endotracheal tubes by oxygen glow discharge to reduce bacterial adhesion, Surf. Interface Anal. 35 (2003) 301 -309.

[49] Y.H. An, R.J. Friedman, Concise review of mechanisms of bacterial adhesion to biomaterial surfaces, J. Biomed. Mater. Res. 43 (1998) 338-348.

[50] G.J. Tortora, B.R. Funke, C.L. Case, Microbiology: An Introduction, Benjamin/Cummings, San Francisco, 2006.

[51] S.G. Hu, C.H. Jou, M.C. Yang, Surface grafting of polyester fiber with chitosan and the antibacterial activity of pathogenic bacteria, J. Appl. Polym. Sci. 86 (2002) 2977-2983.

[52] S.G. Hu, C.H. Jou, M.C. Yang, Antibacterial and biodegradable properties of polyhydroxyalkanoates grafted with chitosan and chitooligosaccharides via ozone treatment, J. Appl. Polym. Sci. 88 (2003) 2797-2803. 